\title{
A Leader: One, Who Knows the Way, Goes the Way and Shows the Way
}

\author{
Almas Sabir \\ College of Business Administration, University of Hail, Hail, Kingdom of Saudi Arabia \\ Email address: \\ almas.sabir083@gmail.com \\ To cite this article: \\ Almas Sabir. A Leader: One, Who Knows the Way, Goes the Way and Shows the Way. European Business \& Management. \\ Vol. 3, No. 5, 2017, pp. 82-85. doi: 10.11648/j.ebm.20170305.12 \\ Received: October 10, 2017; Accepted: October 30, 2017; Published: November 15, 2017

\begin{abstract}
Every leader has their own style and strategy. Further, leadership styles and methods vary because of outside influences and personal challenges. Leaders do not exist to order their workers around. While they oversee their team, a true leader takes initiative and trusts their employees to perform efficiently and independently. In this paper I would like to highlight how person holds a dominant or superior position within its field, and is able to exercise a high degree of control or influence over others. Another important point I would like to explain the potential of leaders for influencing the behavior of others and inducing the subordinates to work with confidence and zeal as well.
\end{abstract}

Keywords: Leaders, Managers, Responsibilities, Styles, Competencies, Behavior

\section{Introduction}

The world we want to experience is where everyone leads with integrity and embraces living in possibility. Where anything is possible, where everyone sees their own gifts and finds ways to use them for the greater good. We want to see our best selves. Time, thought and dedication are the real skill that is needed by a team or group. Leadership is the most studied aspect of business and organization because it is the one overarching topic that makes the difference between success and failure. Management is generally seen to involve overseeing day-to-day operations, accomplishing goals and achieving tasks, while leadership spans a wider remit that includes influencing and inspiring others, generating ideas and defining a strategy and vision. In the table below you will see a direct comparison between leadership and management activities. An individual can be a great leader, a great manager, or both, but each area requires the mastery of slightly different skills and competencies.

Leadership is a process by which an executive can direct, guide and influence the behavior and work of others towards accomplishment of specific goals in a given situation. Leadership is the ability of a manager to induce the subordinates to work with confidence and zeal.

Leadership is the potential to influence behavior of others. It is also defined as the capacity to influence a group towards the realization of a goal. Leaders are required to develop future visions, and to motivate the organizational members to want to achieve the visions.

According to Keith Davis, "Leadership is the ability to persuade others to seek defined objectives enthusiastically. It is the human factor which binds a group together and motivates it towards goals."

\subsection{Characteristics of Leadership}

1. It is an inter-personal process in which a manager is into influencing and guiding workers towards attainment of goals.

2. It denotes a few qualities to be present in a person which includes intelligence, maturity and personality.

3. It is a group process. It involves two or more people interacting with each other.

4. A leader is involved in shaping and molding the behavior of the group towards accomplishment of organizational goals.

5. Leadership is situation bound. There is no best style of leadership. It all depends upon tackling with the situations

Leaders help themselves and others to do the right things. They set direction, build an inspiring vision, and create something new. Leadership is about mapping out where you need to go to "win" as a team or an organization; and it is 
dynamic, exciting, and inspiring.

Yet, while leaders set the direction, they must also use management skills to guide their people to the right destination, in a smooth and efficient way.

Leadership development entails nurturing, encouraging, incubating, and mentoring prospective leaders. In many organizations, the HR department in conjunction with senior management identifies potential leaders or fast trackers who are capable and ensures that they are motivated and encouraged to give their best. This form of mentoring and coaching of future leaders happens through organizational commitment to their development that includes sending them to specialized training programs, making them attend targeted workshops, and taking them to resorts and getaways with the express purpose of ensuring that these prospective leaders get all the encouragement and strategies to groom them into senior level positions.

It needs to be remembered that leadership development is not only about the organizational need for grooming prospective leaders but also to do with the candidates themselves showing the inclination and the aptitude to be groomed as leaders.

\subsection{Importance of Leadership}

Leadership is an important function of management which helps to maximize efficiency and to achieve organizational goals. The following points justify the importance of leadership in a concern.

1. Initiates action- Leader is a person who starts the work by communicating the policies and plans to the subordinates from where the work actually starts.

2. Motivation- A leader proves to be playing an incentive role in the concern's working. He motivates the employees with economic and non-economic rewards and thereby gets the work from the subordinates.

3. Providing guidance- A leader has to not only supervise but also play a guiding role for the subordinates. Guidance here means instructing the subordinates the way they have to perform their work effectively and efficiently.

4. Creating confidence- Confidence is an important factor which can be achieved through expressing the work efforts to the subordinates, explaining them clearly their role and giving them guidelines to achieve the goals effectively. It is also important to hear the employees with regards to their complaints and problems.

5. Building morale- Morale denotes willing co-operation of the employees towards their work and getting them into confidence and winning their trust. A leader can be a morale booster by achieving full co-operation so that they perform with best of their abilities as they work to achieve goals.

6. Builds work environment- Management is getting things done from people. An efficient work environment helps in sound and stable growth. Therefore, human relations should be kept into mind by a leader. He should have personal contacts with employees and should listen to their problems and solve them. He should treat employees on humanitarian terms.

7. Co-ordination- Co-ordination can be achieved through reconciling personal interests with organizational goals. This synchronization can be achieved through proper and effective co-ordination which should be primary motive of a leader.

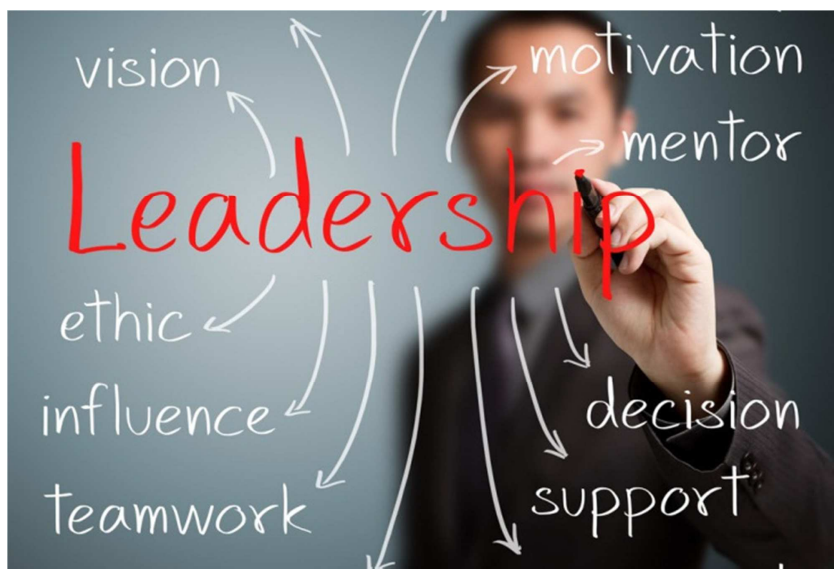

Figure 1. Different strategies of good leader.

\section{Literature Review}

Introducing Leadership is not about famous explorers or corporate CEOs - in fact, they are rarely mentioned - but all about the everyday leadership by first line and middle managers of people working in their organizations. Its emphasis is severely practical because it starts from the assumption that leadership is based on skills and behaviors that most people can acquire, and that most of the people working in organizations want effective leadership from the people who manage them on a day-to-day basis. However, it is for all the hard-pressed managers in your organization who have to motivate and inspire the people who perform the tasks that make the organization function on a day-to-day basis.

There is widespread agreement between industry, regulators, academics and the press that leadership is a key component of a safe organization. This view is widely supported by findings from almost all major incident inquiries and investigations. However, the widespread agreement that leadership is central to safety does not extend to how leadership should deliver safety, what needs to be done, and rather importantly, who should be doing it. While there is considerable literature on leadership, very little of this addresses the issue of safety, particularly in the major hazard sector.

Aim of the Review

The aim of the review is to identify specific leadership styles, attitudes, behaviors and practices that represent effective leadership for safety. The specific objectives are to:

1. Carry out a review of key leadership literature in the 
appropriate business domains.

2. Evaluate different leadership theories and determine their appropriateness for the management of safety risks.

3. Based on the literature and subsequent analysis, develop a framework describing the key requirements of safety leadership.

The word "leadership" can bring to mind a variety of images. For example:

1. A political leader, pursuing a passionate, personal cause.

2. An explorer, cutting a path through the jungle for the rest of his group to follow.

3. An executive, developing her company's strategy to beat the competition.

Leaders help themselves and others to do the right things. They set direction, build an inspiring vision, and create something new. Leadership is about mapping out where you need to go to "win" as a team or an organization; and it is dynamic, exciting, and inspiring.

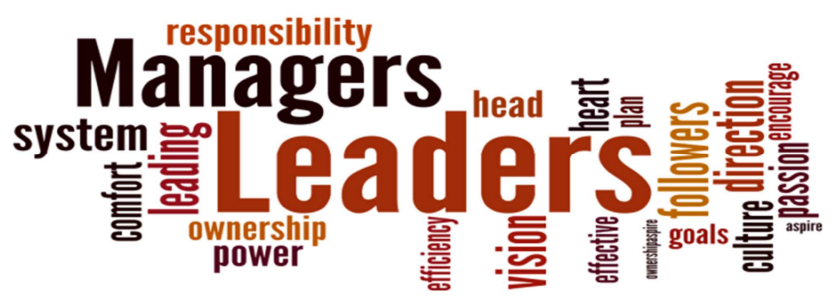

Figure 2. Vision of Manager.

Perhaps there was a time when the calling of the manager and that of the leader could be separated. A foreman in an industrial-era factory probably didn't have to give much thought to what he was producing or to the people who were producing it. His or her job was to follow orders, organize the work, assign the right people to the necessary tasks, coordinate the results, and ensure the job got done as ordered. The focus was on efficiency.

But in the new economy, where value comes increasingly from the knowledge of people, and where workers are no longer undifferentiated cogs in an industrial machine, management and leadership are not easily separated. People look to their managers, not just to assign them a task, but to define for them a purpose. And managers must organize workers, not just to maximize efficiency, but to nurture skills, develop talent and inspire results.

The late management guru Peter Ducker was one of the first to recognize this truth, as he was to recognize so many other management truths. He identified the emergence of the "knowledge worker," and the profound differences that would cause in the way business was organized.

With the rise of the knowledge worker, "one does not 'manage' people," Mr. Drucker wrote. "The task is to lead people. And the goal is to make productive the specific strengths and knowledge of every individual." The words "leader" and "manager" are among the most commonly used words in business and are often used interchangeably.

\section{Methods}

This program examines the difficult interpersonal and strategic problems involved in successfully spearheading change. It provides frameworks, models, and perspectives on leading change that can applied to unique challenges.

\subsection{Qualitative and Quantitative Distinctions}

According to F. Williams (1992), there are two major methodological research traditions: qualitative and quantitative methods.

Quantitative methods should be utilized when the phenomenon under study needs to be measured, when hypotheses need to be tested, when generalizations are required to be made of the measures, and when generalizations need to be made that are beyond chance occurrences. As noted by Williams, "if measures are not apparent or if researchers cannot develop them with confidence.

Quantitative methods are not appropriate to the problem". Thus, choice of which approach to use will depend on a number of factors.

\subsection{Management Program Highlights \& Benefits}

a. Valuable insights that will broaden your understanding of and alter your perspective on change

b. Specific applications, frameworks, and techniques that will help you drive behavioral change throughout your organization

c. Targeted change initiatives and challenge-specific strategies for use in your current workplace scenarios.

The writings of Taylor, Fayol, Likert, and others suggest that there is "one best way" to lead and manage. Nevertheless, there is no generally accepted leadership methodology consisting of the sequence of actions, traits, and skills that result in goal achievement.

\section{Result}

Understanding and conducting leadership research requires knowledge of research methodology. In this an overview of important elements relating to the use of research methods and procedures for studying and making inferences about leadership is provided. I tried in my paper to highlight for readers with useful pointers for conducting and for assessing the quality of leadership research. Apart from a basic review, we also cover some advanced topics that should be interesting to researchers and graduate students. Where possible, an attempt is made to write the usefulness of mostly nontechnical and no statistical terminology so that its contents are accessible to a comparatively large audience.

\section{Discussion}

The main difference between leaders and managers is that leaders have people follow them while managers have people who work for them. A successful business owner needs to be 
both a strong leader and manager to get their team on board to follow them towards their vision of success.

Main differences:

1. The manager maintains; the leader develops.

2. The manager focuses on systems and structure; the leader focuses on people.

3. The manager relies on control; the leader inspires trust.

4. The manager has a short-range view; the leader has a long-range perspective.

5. The manager asks how and when; the leader asks what and why.

6. The manager has his or her eye always on the bottom line; the leader's eye is on the horizon.

7. The manager imitates; the leader originates.

8. The manager accepts the status quo; the leader challenges it.

9. The manager is the classic good soldier, the leader is his or her own person, the manager does things right, the leader does the right thing

Leadership can be hard to define and it means different things to different people.

In the transformational leadership model, leaders set direction and help themselves and others to do the right thing to move forward. To do this they create an inspiring vision, and then motivate and inspire others to reach that vision. They also manage delivery of the vision, either directly or indirectly, and build and coach their teams to make them ever stronger.

Effective leadership is about all of this - and it's exciting to be part of this journey!

\section{Conclusion}

The words "leader" and "leadership" are often used incorrectly to describe people who are actually managing. These individuals may be highly skilled, good at their jobs, and valuable to their organizations - but that just makes them excellent managers, not leaders.

So, be careful how you use the terms, and don't assume that people with "leader" in their job titles, people who describe themselves as "leaders," or even groups called "leadership teams" are actually creating and delivering transformational change.

A particular danger in these situations is that people or organizations that are being managed by such an individual or group think they're being led; but they're not. There may actually be no leadership at all, with no one setting a vision and no one being inspired. This can cause serious problems in the long term.

\section{References}

[1] 4 Ways to Define Leadership, http://www.businessnewsdaily.com

[2] https://www.abdn.ac.uk/develop/managers/introduction-toleadership

[3] http://managementstudyguide.com/leadership

[4] www.mindtools.com/pages/article

[5] https://managementstudyguide.com/leadership-development.

[6] http://managementstudyguide.com/importance_of_leadership

[7] Copyright (C) 2007 David Pardey. Published by Elsevier Ltd All rights reserved, page- 2

[8] A review of literature on effective leadership behaviors for safety, http:/www.hse.gov.uk/research/rrpdf/rr952.pdf

[9] What Is Leadership? www.mindtools.com/pages/article

[10] http://guides.wsj.com/management/developing-a-leadershipstyle/what-is-the-difference-between-management-andleadership

[11] https://us.corwin.com/sites/default/files/upmbinaries/5013_Antonakis_Chapter_3.pdf 